\title{
Effect of Various Physical Parameters and Statistical Medium Optimization on Production of Hyaluronic Acid Using S. Equi Subsp. Zooepidemicus ATCC 39920
}

\section{RESEARCH ARTICLE}

\author{
VJ. Aroskar, SD Kamat and DV Kamat* \\ Department of Microbiology, Mithibai College of Arts, Chauhan Institute of Science \& Amruthben Jivanlal College of Commerce and \\ Economics, Vile Parle (W), Mumbai 400 056, INDIA
}

\begin{abstract}
It has been shown that initial conditions for bacterial cultivation are extremely important for the successful production of hyaluronic acid $(\mathrm{HA})$ by fermentation. We investigated several physical parameters that affect productivity of $\mathrm{HA}$ under shake flask. i.e. transfer criteria of seed, agitation and aeration of fermentation flasks. Among the various physical parameters studied, inoculum age of $8-10 \mathrm{~h}, \mathrm{pH} 6.4$, optical density $(600 \mathrm{~nm}) 2.0$ and $3 \%$ level inoculum transfer found to be optimum. After inoculating with Streptococcus equi subsp. zooepidemicus ATCC 39920 , the temperature $37{ }^{\circ} \mathrm{C}$ and 90 rpm found optimum during growth as well as for the HA production. The fractional factorial design of six factors with two levels showed yeast extract, potassium dihydrogen phosphate and sodium bicarbonate as significant model terms. The factor potassium dihydrogen phosphate was relatively more significant than yeast extract.
\end{abstract}

Received on: 12 Mar. 2012

Accepted on: 12 Apr. 2012

Published on: 16 Jan. 2013

DOI: $10.5195 /$ iioablett.2012.17

Keywords: Streptococcus zooepidemicus; Hyaluronic acid; Shake flask fermentation; Fractional factorial design; Statistical model; Physical parameters

\section{INTRODUCTION}

Hyaluronic acid (HA) is a high molecular weight glycosaminoglycan. Markovitz et al, (1959) reported the synthesis of HA using UDP -glucuronic acid and UDP $\mathrm{N}$-acetyl glucosamine as substrates and the streptococcal -membrane-associated enzyme hyaluronate synthase as catalyst. Naturally, HA occurs in bacteria as a mucoid capsule surrounding the cell, and in soft tissues and the vitreous humor of the eye, in higher animals including human beings (O'Regan et al, 1994). It has been applied in clinical therapy and clinical diagnoses due to its high biocompability and many important physiological functions eg. arthral lubrication, diffusion \& transportation of protein, maintenance of water \& electrolyte and acceleration of wound healing (Swann and Kuo, 1991) .

The commercial HA can be extracted from rooster combs or produced by microbial production of group A and C Streptococci owing to the fact that the use of animal derived biochemicals for human therapeutics is being met with opposition because of the risk of cross species viral infection. Hence, the microbial production is gradually replacing extraction as a preferred source of HA. Currently, the commonly used strain for microbial HA production at an industrial scale is Streptococcus zooepidemicus which synthesizes HA as the extra cellular capsule (Duan et al, 2008). Although many studies have been performed an HA production, there are no reports on statistical optimization. Thus the present study showed the optimization of HA production at various physical parameters under shake flask conditions by $S$. equi subsp. zooepidemicus ATCC 39920.

\section{MATERIALS AND METHODS}

\section{Bacterial Strain}

Streptococcus equi subsp. zooepidemicus ATCC 39920 was obtained from American type culture collection, ATCC (USA). The strain was maintained and preserved on agar slants and in glycerol stock at $4^{0}$ and $-80^{\circ} \mathrm{C}$, respectively.

\section{Cultivation}

Seed culture development was carried out in a $250 \mathrm{ml}$ Erlenmeyer flask with $50 \mathrm{ml}$ of the P10 medium which contained (per liter) $10 \mathrm{~g}$ peptone bacteriological, $5.0 \mathrm{~g}$ yeast extract, $10.0 \mathrm{~g} \mathrm{KH}_{2} \mathrm{PO}_{4}, 5.0 \mathrm{~g} \mathrm{C}_{2} \mathrm{H}_{4} \mathrm{NaO}_{2} .3 \mathrm{H}_{2} \mathrm{O}$, 3.0g $\mathrm{NaHCO}_{3}$, and $7.5 \mathrm{ml}$ salt solution [The composition of the salt solution per liter: $1.0 \mathrm{~g} \quad \mathrm{FeSO}_{4} .7 \mathrm{H}_{2} \mathrm{O}, 20.0 \mathrm{~g}$ $\mathrm{MgSO}_{4} .7 \mathrm{H}_{2} \mathrm{O}, 1.0 \mathrm{~g} \quad \mathrm{MnSO}_{4} .4 \mathrm{H}_{2} \mathrm{O}, 5.0 \mathrm{~g} \quad \mathrm{CaCl}_{2} .2 \mathrm{H}_{2} \mathrm{O}$, $46.0 \mathrm{~g} \quad \mathrm{Na}_{2}$ EDTA.2 $\left.\mathrm{H}_{2} \mathrm{O}\right], \mathrm{pH}$ 6.8-6.9. Total $47 \mathrm{ml}$ of medium was dispensed in $250 \mathrm{ml}$ conical flask and 
sterilized at $121^{\circ} \mathrm{C}$ for 20 minutes. After sterilization, 3.0 $\mathrm{ml}$ of dextrose solution (50\% prepared and sterilized separately) and $2.0 \mathrm{ml}$ of calcium carbonate solution (25 $\%$ prepared and separately sterilized) was added. Modification of the medium used by Vazquez et al, (2009) was used. In P10 medium concentration of potassium dihydrogen phosphate is more. In earlier reported medium of Vazquez et al, (2009) the potassium dihydrogen phosphate is $2 \mathrm{~g} / \mathrm{L}$ whereas in P10 medium it is $10 \mathrm{~g} / \mathrm{L}$. Also sodium acetate, sodium bicarbonate and salt solution is additional in P10 medium which is not there in medium by Vazquez et al, (2009).The P10 medium was also used as a seed medium. Conditions for shake flask fermentation: One $\mathrm{ml}$ of Streptococcus equi subsp. zooepidemicus ATCC 39920 frozen glycerol stock was transferred to $50 \mathrm{ml}$ vegetative medium in $250 \mathrm{ml}$ Erlenmeyer flasks. The flask was incubated at $37^{\circ} \mathrm{C}$ and $90 \mathrm{rpm}$ at $5 \mathrm{~cm}$ displacement for 7-12 h (Scigenics shaker). When the $\mathrm{pH}$ of the seed reached between 6.36.4 and optical density at $600 \mathrm{~nm}$ reached 2.0 in P10 medium, $1.5 \mathrm{ml}$ of the inoculum was transferred to the $50 \mathrm{ml}$ fermentation medium. The inoculated fermentation shake flasks were incubated at $37^{\circ} \mathrm{C}$ at 90 rpm. After 24 hours the flasks were harvested and analyzed for $\mathrm{pH}, \mathrm{OD}$ and yield of $\mathrm{HA}$.

\section{Analytical Methods}

Cell and optical density of the broth was measured at $600 \mathrm{~nm}$ with a spectrophotometer (Shimadzu, UV120-02, Japan). Total sugar was measured using Anthrone's reagent method (Trevelyan et al., 1952).

\section{HA Quantification}

In the measurement of HA concentration, the fermented broth sample was first diluted with water and centrifuged at $3000 \mathrm{rpm}$ for 5 minutes to remove solid mass. The resulted supernatant solution was then subjected to HA precipitation by mixing with two volumes of ethanol. The precipitate was collected by centrifugation at $3000 \mathrm{rpm}$ for 20 minutes and the precipitate was redissolved in water.To this was then added disodium tetraborate solution and boiled for 10 minutes. After cooling to room temperature, carbazole solution was added and heated in water bath for 15 minutes and read at $525 \mathrm{~nm}$ with D-glucuronic acid as the standard (Bitter and Muir, 1962).

\section{Effect of Various Parameters on HA production}

Effect of various physical parameters on HA production like optical density (1.5-2 at 600nm), pH (5.5-6.6), temperature $\left(30-40^{\circ} \mathrm{C}\right)$, agitation (50-150rpm) and different cultivation volume $(25-100 \mathrm{ml})$ were studied in P10 medium under shake flask.

\section{Media Optimization by Two Level Factorial Fractional Designs (FFD)}

Two level fractional (1/2 fraction) design was employed for P10 medium. Table 1 shows minimum and maximum concentration of P10 medium ingredient.

Table 1. Minimum and maximum concentration of media ingredients of $P 10$ medium in

fractional factorial design.

\begin{tabular}{clcc} 
Code & Factor & $\begin{array}{c}\text { Minimum (-) } \\
\text { Concentration (g/L) }\end{array}$ & $\begin{array}{c}\text { Maximum (+) } \\
\text { Concentration } \\
(\mathbf{g} / \mathbf{L})\end{array}$ \\
\hline A & Peptone & 10.0 & 20.0 \\
B & Yeast extract & 3.0 & 7.0 \\
C & $\mathrm{KH}_{2} \mathrm{PO}_{4}$ & 5.0 & 15.0 \\
D & Sodium acetate trihydrate & 3.0 & 7.0 \\
E & Sodium bi carbonate & 2.0 & 4.0 \\
F & Dextrose & 20.0 & 40.0
\end{tabular}

Effect of peptone, yeast extract, $\mathrm{KH}_{2} \mathrm{PO}_{4}$, sodium acetate trihydrate, sodium bicarbonate and dextrose on maximum HA production was investigated using Two level fractional (1/2 fraction) design. Factorial designs are to check the important parameters that are affecting production of HA along with interaction between the variables. The six factors (peptone, yeast extract, $\mathrm{KH}_{2} \mathrm{PO}_{4}$, sodium acetate trihydrate, sodium bicarbonate and dextrose) examined at two levels are as listed in Table 1. The choice of levels of the factors was based on information from literature and preliminary experiments. A two level fractional factorial design (1/2 frac) experiment was conducted in triplicate with $S$. equi subsp. zooepidemicus ATCC 39920. The total 32 experiments were carried out at randomized run order. The response variable selected was the maximum concentration of HA. Results were analyzed using analysis of variance (ANOVA) using software (Design Expert version 6.0.10, Stat-Ease, Minneapolis, MN, USA). On connecting the points for each factor, the line is created which states the significance. The parallel line to the axis represents no significant effect. However the diagonal line to the axis represents a significant effect. 


\section{RESULTS AND DISCUSSIONS}

\section{Effect of Various Physical Parameters on HA Production}

The P10 medium was developed both for inoculam and shake flask fermentation. P10 medium contained required factors. Production of HA was studied using P10 medium containing glucose and peptone as carbon and nitrogen sources respectively, after $24 \mathrm{~h}$, HA yield of $0.70 \pm 0.03 \mathrm{~g} / \mathrm{L}$ was obtained.

When preparing inoculum the requirement is a fast growing culture where metabolic pathways are induced and then culture can immediately start multiplying in production medium. If the inoculum is suboptimal then it turns to die in the production cycle or starts to grow at the expense of producing the product thus delaying the yield time. In order to study the effect of the culture age in the seed media, experiments were conducted by transferring different age of seed (like $8 \mathrm{~h} 14 \mathrm{~h}$ and $20 \mathrm{~h}$ ) to the fermentation media. The age of culture was fixed as a range from $\log 08$ to $\log 14$ in which the yield in fermentation media was $0.73 \mathrm{~g} / \mathrm{L}$ and $0.7 \mathrm{~g} / \mathrm{L}$ respectively. The maturity parameters are achieved at 08-10 $\mathrm{h}$ with $\mathrm{pH}$ 6.3-6.4 and $\mathrm{A}_{600}$ greater than 2.0. Huang et al., (2007) proposed the same age as the log phase with greater cell number and cell mass in Streptococcus equi subsp. zooepidemicus ATCC 39920 for production of HA.

Inoculam between $2 \%$ and $5 \%$ has shown better yield. Higher concentrations have not proven worthwhile. Higher concentration tend to shift the fermentation to a growth cycle phenomenon and to produce other pathways, major metabolic pathway which are delicately balanced will tend to be over- ridden. If the inoculum is low then it tends to die and or take much longer time to go to $\log$ phase. The study revealed that $3 \%$ inoculum as the optimum and there was no significant difference between the $3 \%$ and $5 \%$ inoculum. When $10 \%$ inoculum was used the batch shown less yield than the batch with $3 \%$ inoculum (Table 2). Addition of high amount of inoculum such as $10 \%$ increases the sugar consumption at the initial phases and the $\mathrm{pH}$ drop was high in such case. Increasing the inoculum percentage allows the parameters to achieve earlier with high sugar consumption that favoring growth at the most extent. In case of HA production, the growth rate should be comparatively low than the HA production rate.
Table 2. Effect of inoculum level on HA production by S. equi subsp. zooepidemicus ATCC

39920 using P10 medium

Inoculum level (\%) HA Yield ( $g / L)$

1

$0.62 \pm 0.03$

2

$0.65 \pm 0.03$

3

5

10

$0.70 \pm 0.04$

$0.64 \pm 0.03$

$0.64 \pm 0.03$

\pm indicates standard deviation; The medium $(50 \mathrm{ml})$ in $250 \mathrm{ml}$ Erlenmeyer flask, after

inoculating with $S$. equi subsp. zooepidemicus ATCC $39920\left(\mathrm{~A}_{600} 2.0, \mathrm{pH} 6.3\right.$ and 1\%, 3\%, 5\%

and $10 \%$ level) was incubated at $37^{\circ} \mathrm{C} \pm 1$ on an orbital shaker ( $90 \mathrm{rpm}$ ) for $24 \mathrm{~h}$

Optimal oxygen must be provided such that the organism grows in a reproducible metabolic pattern, which in turn is best suited for the production of secondary desired metabolites. Higher aeration will induce undesirable pathways and metabolites that may be toxic to the organisms. Higher level of oxygen is suppressive for secondary metabolite pathways in general. The growth and production of HA was screened in the static and aerobic conditions. The aerobic conditions gave good yield of $0.70 \pm 0.03 \mathrm{~g} / \mathrm{L}$ in the P10 medium. Under Static conditions the HA production was low reaching up to $0.50 \pm 0.02 \mathrm{~g} / \mathrm{L}$. The organism Streptococcus species require minimum critical concentration of dissolved oxygen in the medium to grow well and produce HA (Swann et al., 1990). Duan et al. (2006) reported that under anaerobic conditions the organism do not replicate fast or produce HA in huge amounts when compared to aerated conditions.

\section{Fermentation Period}

Fermentation period will be depend on the product is being synthesized and is desirable in optimal yield. Therefore harvesting has to be product concentration related. It is not advisable to continue fermentation over long cycle unless it is a fed batch mode where periodic harvesting is used. In order to determine the fermentation period, where maximum productivity is obtained the broth was harvested at different time at regular intervals and estimated the HA yield. At $\log 16$, the maximum productivity of HA $(0.70 \mathrm{~g} / \mathrm{L})$ was observed whereas at $24 \mathrm{~h}$ also the HA in fermentation broth found to be $0.70 \mathrm{~g} / \mathrm{L}$. For the shake flask experiments the $24 \mathrm{~h}$ fully fermented broth was taken for analysis and it is kept constant for the batches to be taken in fermenter, simultaneous HA assay and viscosity 
measurements were carried out to predetermine the reduction in the HA production at late hours. The organism is a fast growing organism which attains its maximum HA production at $\log 16$ under the provided conditions (Chong et al., 2005).

\section{Determination of the Seed Maturity Parameters}

\section{Effect of Optical Density of Seed}

The seed maturity parameters are optimized, especially the optical density of the seed. The seed from the lab shake flask at different optical densities $(1.4,1.6,2.0,2.4$ and 2.8 at $600 \mathrm{~nm}$ ) were studied by transferring them to shake flask fermentation medium. It was found that the optical density should be in the range from 1.5 to 2.2 to obtain better HA yield. Optical density greater than this limit such as 2.4 and 2.8 gave considerably less yield. The low yield of HA was obtained when optical density $\left(\mathrm{A}_{600}\right)$ of inoculam was 2.8 (Table 3).

Table 3. Effect of optical density of seed on HA production by S. equi subsp. zooepidemicus ATCC 39920 using P10 medium

\begin{tabular}{|cc|}
\hline Optical density $\mathbf{A}_{600}$ & HA Yield $(\mathbf{g} / \mathbf{L})$ \\
\hline 1.4 & $0.58 \pm 0.03$ \\
1.6 & $0.66 \pm 0.03$ \\
2.0 & $0.70 \pm 0.03$ \\
2.4 & $0.65 \pm 0.03$ \\
2.8 & $0.57 \pm 0.02$ \\
\hline
\end{tabular}

The medium $(50 \mathrm{ml})$ in $250 \mathrm{ml}$ Erlenmeyer flask, after inoculating with $S$. equi subsp zooepidemicus ATCC $39920\left(A_{600}=1.4,1.6,2.0,2.4\right.$ and $2.8,3 \%$ level $)$ was incubated at $37^{\circ} \mathrm{C}$ \pm 1 on an orbital shaker $(90 \mathrm{rpm})$ for $24 \mathrm{~h}$.

\section{Effect of Transfer $\mathrm{pH}$ of Seed}

Various $\mathrm{pH}$ ranges 5.5, 5.8, 6.2, 6.4, 6.6 were tested for determining the transfer criteria. The fermentation media inoculated with the seed at $\mathrm{pH} 6.4$ gave maximum yield of $0.70 \mathrm{~g} / \mathrm{L}, 6.2$ gave $0.68 \mathrm{~g} / \mathrm{L}$ whereas the $\mathrm{pH} 5.5,5.8$ and 6.6 gave less yield of $0.55,0.60$ and $0.65 \mathrm{~g} / \mathrm{L}$ respectively. The effect of lab seed $\mathrm{pH}$ as a transfer criterion was studied and determined that 6.2 to 6.4 as the range at which the organism reaches the active mid log phase. Hence at this stage the OD will be reaching 2.0 when measured at $600 \mathrm{~nm}$. At the $\mathrm{pH}$ of 5.5 or 6.0 (which is highly acidic) the organism reached its late log phase and then stationary phase which are not the perfect time for the transfer to fermentation medium.

\section{Effect of Fermentation $\mathrm{pH}$}

Hyaluronate synthase which catalyzed the polymerization of HA was reported to have maximum activity at pH 7.1 in cell free extracts (Stool miller and Dorfman, 1969). Akasaka et al, (1988) reported that $\mathrm{pH}$ 7.4 gave the highest viscosity compared to $\mathrm{pH} 6.0$ and 7.9. The fermentation media were adjusted to different $\mathrm{pH}$ of 6.0, 6.5 and 7.0, in which the $\mathrm{pH} 7.0$ was found as optimum for the production of HA and growth as shown in Table 4. The $\mathrm{pH}$ of the fermentation medium was adjusted at 7.0. The organism grows well and produces lactic acid and acetate which reduces the $\mathrm{pH}$ from 7.0 to 5.5 around during the harvest. Addition of calcium carbonate at a concentration of $10.0 \mathrm{~g} / \mathrm{L}$, act as a buffering agent and prevents the $\mathrm{pH}$ from going down towards acidic region. The neutral $\mathrm{pH}$ is the optimum $\mathrm{pH}$ for the organism to grow well and produce HA. At acidic $\mathrm{pH}$ the production of $\mathrm{HA}$ gets inhibited (Jagannath and Ramchandran, 2010).

Table 4. Effect of fermentation pH on HA production by S. equi subsp. zooepidemicus ATCC 39920 using P10 medium

\begin{tabular}{|cc|}
\hline Fermentation $\mathbf{p H}$ & HA Yield (g/L) \\
\hline 6.0 & $0.50 \pm 0.02$ \\
6.5 & $0.65 \pm 0.03$ \\
7.0 & $0.70 \pm 0.03$ \\
7.5 & $0.65 \pm 0.03$ \\
\hline
\end{tabular}

The medium ( $50 \mathrm{ml}$ ) with different fermentation $\mathrm{pH}$ in $250 \mathrm{ml}$ Erlenmeyer flask, after inoculating with S. equi subsp. zooepidemicus ATCC $39920\left(A_{600}=2.0, \mathrm{pH} 6.3,3 \%\right.$ level $)$ was incubated at $37^{\circ} \mathrm{C} \pm 1$ on an orbital shaker (90 rpm) for $24 \mathrm{~h}$.

\section{Effect of Agitation Speed}

Different agitation speed of 50, 70, 90, 110 and $150 \mathrm{rpm}$ was studied in a shaker with displacement $5 \mathrm{~cm}$. Shaking at 70-90 rpm was found more significant for the production of HA as shown in Table 5. Increasing the turbulence more than $90 \mathrm{rpm}$ increases the shear over the organism which might affect the production of HA.

\section{Effect of Temperature}

Fermentation shake flask was tested at different temperatures such as $32^{\circ} \mathrm{C}, 35^{\circ} \mathrm{C}, 37^{\circ} \mathrm{C}$ and $40^{\circ} \mathrm{C}$ among which the $37^{\circ} \mathrm{C}$ was found to be the optimum for the production of HA and growth of the organism as shown in Table 6. The optimum temperature for the growth and 
HA production was found to be $37^{\circ} \mathrm{C}$. Suboptimal temperature growth has been reported to have aided the synthesis of high molecular weight HA (Armstrong and Johns, 1997).

Table 5. Effect of agitation speed on HA production by S. equi subsp. zooepidemicus ATCC 39920 using P10 medium

\begin{tabular}{|cc|}
\hline Agitation speed $(\mathbf{r p m})$ & HA Yield $(\mathbf{g} / \mathbf{L})$ \\
\hline 50 & $0.62 \pm 0.03$ \\
70 & $0.69 \pm 0.03$ \\
90 & $0.72 \pm 0.03$ \\
110 & $0.68 \pm 0.03$ \\
150 & $0.65 \pm 0.03$ \\
\hline
\end{tabular}

The medium (50 $\mathrm{ml}$ ) with different fermentation $\mathrm{pH}$ in $250 \mathrm{ml}$ Erlenmeyer flask, after inoculating with S. equi subsp. zooepidemicus ATCC $39920\left(\mathrm{~A}_{600}=2.0, \mathrm{pH} 6.3,3 \%\right.$ level) was incubated at $37^{\circ} \mathrm{C} \pm 1$ on an orbital shaker $(50,70,90,110$ and $150 \mathrm{rpm})$ for $24 \mathrm{~h}$.

Table 6. Effect of temperature on HA production by $S$. equi subsp. zooepidemicus ATCC 39920 using P10 medium

\begin{tabular}{|cc|}
\hline Temperature $\left({ }^{\circ} \mathbf{C}\right)$ & HA Yield $(\mathbf{g} / \mathbf{L})$ \\
\hline 32 & $0.64 \pm 0.03$ \\
35 & $0.68 \pm 0.03$ \\
37 & $0.70 \pm 0.03$ \\
40 & $0.62 \pm 0.03$ \\
\hline
\end{tabular}

The medium $(50 \mathrm{ml})$ with different fermentation $\mathrm{pH}$ in $250 \mathrm{ml}$ Erlenmeyer flask, after inoculating with S. equi subsp. zooepidemicus ATCC $39920\left(\mathrm{~A}_{600}=2.0, \mathrm{pH} 6.3,3 \%\right.$ level) was incubated at 32,3537 , and $40^{\circ} \mathrm{C} \pm 1$ on an orbital shaker (90 rpm) for $24 \mathrm{~h}$.

Table 7. Effect of volume of medium on HA production by S. equi subsp. zooepidemicus ATCC 39920 using P10 medium

\begin{tabular}{|ccc|}
\hline $\begin{array}{c}\text { Media volume to flask volume } \\
(\mathbf{m l})\end{array}$ & $\begin{array}{c}\text { Media volume to flask volume } \\
\text { ratio }\end{array}$ & HA Yield $(\mathbf{g} / \mathbf{L}))$ \\
$25 / 250 \mathrm{ml}$ & 0.10 & $0.65 \pm 0.03$ \\
$50 / 250 \mathrm{ml}$ & 0.20 & $0.70 \pm 0.03$ \\
$75 / 250 \mathrm{ml}$ & 0.30 & $0.65 \pm 0.03$ \\
$100 / 250 \mathrm{ml}$ & 0.40 & $0.62 \pm 0.03$ \\
\hline
\end{tabular}

\section{Effect of Cultivation Volume}

Different volume of media was used ranging from 100 $\mathrm{ml}$ in $250 \mathrm{ml}, 75 \mathrm{ml}$ in $250 \mathrm{ml}, 50 \mathrm{ml}$ in $250 \mathrm{ml}$ and finally $25 \mathrm{ml}$ in $100 \mathrm{ml}$. Decreasing the volume of medium in $250 \mathrm{ml}$ flasks increased the productivity of HA. 50 $\mathrm{ml} / 250 \mathrm{ml}$ medium to volume ratio of 0.2 found to be optimum (Table 7). The addition of $75 \mathrm{ml}$ or $100 \mathrm{ml}$ medium to the $250 \mathrm{ml}$ affected the mass transfer.

\section{Optimization of HA production under shake flask conditions}

Variations are observed while carrying out shake flask experiments. When growth and HA production started, it has been observed that $\mathrm{pH}$ went down which restricted growth and $\mathrm{HA}$ production. $\mathrm{CaCO}_{3}$ was added to minimize the drop in $\mathrm{pH}$ to acidic side. At fermenter level we have added $3.0 \mathrm{~N} \mathrm{NaOH}$ at automatic mode to maintained $\mathrm{pH}$ near 7.0 throughout the fermentation. It has been observed that the colony selection is an important criteria. Selection of mucoid colony is important. The culture preserved as a glycerol stock at $80^{\circ} \mathrm{C}$ should be used within one month. These factors are important to achieve high and reproducible yield of HA at shake flask and fermenter level.

\section{Media optimization by two level fractional factorial designs P10 medium optimization}

A two level fractional (1/2 frac) experimental design, leading to a total number of 32 experiments (Table 8 ) was employed for the optimization of the parameters. Table 8 also contains an experimental set-up with observed yield of HA (g/L). The coefficient of determination $\left(\mathrm{R}^{2}\right)$ was calculated as 0.9517 for HA production (Table 9), indicating that the statistical model can explain $95.87 \%$ of variability in the response. The $\mathrm{R}^{2}$ value is always between 0 and 1 . The closer the $R^{2}$ is to 1.0, the stronger the model and the better it predicts the response. This indicated a good agreement between the experimental and predicted value for HA production. The model F-value of 6.85 and values of 'prob > F' less than 0.05 indicated that the model terms are significant. For HA production $\mathrm{B}$ (yeast extract), $\mathrm{C}\left(\mathrm{KH}_{2} \mathrm{PO}_{4}\right)$ and $\mathrm{E}$ (sodium bicarbonate) along with $\mathrm{CD}\left(\mathrm{KH}_{2} \mathrm{PO}_{4}\right.$ and sodium acetate), DF (sodium acetate and dextrose), $\mathrm{EF}$ (sodium bicarbonate and dextrose), $\mathrm{ABC}$ (peptone, yeast extract and $\mathrm{KH}_{2} \mathrm{PO}_{4}$ ), $\mathrm{ABE}$ (peptone, yeast extract and dextrose), $\mathrm{ACD}$ (peptone, $\mathrm{KH}_{2} \mathrm{PO}_{4}$ and sodium acetate), $\mathrm{ADE}$ (peptone, sodium acetate and sodium bicarbonate), AEF (peptone, sodium bicarbonate and dextrose) are significant model terms. The final response equation that represented a suitable model for HA production is given as Eq. 1. The factor $\mathrm{KH}_{2} \mathrm{PO}_{4}$ was relatively more significant than yeast extract (Figure 1). On connecting the points for each factor, the line is created which states the significance. The line is parallel to the axis then there is no significant effect. However, the line is diagonal to the axis then there is a significant effect. 
Table 8. Factorial designs for components of P 10 medium in coded form and actual values with their corresponding response in terms of HA production

\begin{tabular}{|c|c|c|c|c|c|c|c|}
\hline Run & A & B & c & D & E & $\mathbf{F}$ & HA Yield $(g / L) \pm S D$ \\
\hline 1 & - & + & - & + & + & + & $0.426 \pm 0.02$ \\
\hline 2 & + & + & - & + & - & + & $0.348 \pm 0.015$ \\
\hline 3 & + & - & - & + & + & + & $0.337 \pm 0.015$ \\
\hline 4 & - & + & + & - & + & + & $0.518 \pm 0.02$ \\
\hline 5 & + & - & + & + & - & - & $0.501 \pm 0.02$ \\
\hline 6 & - & + & + & - & - & - & $0.672 \pm 0.03$ \\
\hline 7 & - & + & + & + & - & + & $0.426 \pm 0.02$ \\
\hline 8 & + & + & - & - & + & + & $0.343 \pm 0.015$ \\
\hline 9 & + & + & + & + & + & + & $0.485 \pm 0.02$ \\
\hline 10 & + & - & + & + & + & - & $0.439 \pm 0.02$ \\
\hline 11 & - & + & - & - & - & + & $0.273 \pm 0.01$ \\
\hline 12 & + & + & + & - & + & - & $0.392 \pm 0.02$ \\
\hline 13 & - & - & + & - & + & - & $0.359 \pm 0.015$ \\
\hline 14 & + & + & + & + & - & - & $0.369 \pm 0.015$ \\
\hline 15 & - & - & + & + & - & - & $0.378 \pm 0.015$ \\
\hline 16 & - & + & + & + & + & - & $0.219 \pm 0.01$ \\
\hline 17 & + & - & - & - & - & + & $0.340 \pm 0.015$ \\
\hline 18 & - & - & - & + & - & + & $0.340 \pm 0.015$ \\
\hline 19 & - & - & - & + & + & - & $0.330 \pm 0.015$ \\
\hline 20 & - & - & + & + & + & + & $0.343 \pm 0.015$ \\
\hline 21 & - & + & - & + & - & - & $0.458 \pm 0.02$ \\
\hline 22 & + & + & - & + & + & - & $0.367 \pm 0.01$ \\
\hline 23 & + & - & + & - & - & - & $0.479 \pm 0.01$ \\
\hline 24 & - & + & - & - & + & - & $0.278 \pm 0.015$ \\
\hline 25 & + & - & - & + & - & - & $0.297 \pm 0.01$ \\
\hline 26 & + & - & + & - & + & + & $0.325 \pm 0.015$ \\
\hline 27 & + & + & + & - & - & + & $0.447 \pm 0.02$ \\
\hline 28 & + & - & - & - & + & - & $0.301 \pm 0.015$ \\
\hline 29 & + & + & - & - & - & - & $0.456 \pm 0.02$ \\
\hline 30 & - & - & - & - & - & - & $0.296 \pm 0.015$ \\
\hline 31 & - & - & + & - & - & + & $0.325 \pm 0.015$ \\
\hline 32 & - & - & - & - & + & + & $0.322 \pm 0.01$ \\
\hline
\end{tabular}

$\mathrm{HA}=0.38+8.219 \mathrm{E}-003$ * $\mathrm{A}+0.024 * \mathrm{~B}+0.036$ * $\mathrm{C}-1.969 \mathrm{E}-$ $003 * \mathrm{D}-0.019 * \mathrm{E}+2.812 \mathrm{E}-04 * \mathrm{~F}-0.012 * \mathrm{~A} * \mathrm{~B}+4.094 \mathrm{E}-$ $003 * \mathrm{~A} * \mathrm{C}+5.719 \mathrm{E}-003 * \mathrm{~A} * \mathrm{D}+3.906 \mathrm{E}-003 * \mathrm{~A}$ * $+1.344 \mathrm{E}-003$ * A * F-2.187E-004 * B * C-6.906E-003 * B * E$0.020 * \mathrm{C} * \mathrm{D}-0.013$ * * E+8.719E-003 * D * E+0.022 * D * $\mathrm{F}+0.026$ * $\mathrm{E} * \mathrm{~F}-0.018$ * $\mathrm{A}$ * $\mathrm{B}$ * $\mathrm{C}+0.018$ * $\mathrm{A}$ * $\mathrm{B}$ * $\mathrm{E}+0.035$ * $A * C * D+0.021 * A * D * E-0.028 * A * E * F$

where, A-peptone, B-yeast extract, $\mathrm{C}-\mathrm{KH}_{2} \mathrm{PO}_{4}$, D-sodium acetate trihydrate, E-sodium bicarbonate, F-dextrose

Table 9. Analysis of variance (ANOVA) for the experimental results of the Fractional factorial design for components of $\mathrm{P} 10$ medium

\begin{tabular}{|c|c|c|c|c|}
\hline Factors & $\begin{array}{l}\text { Sum of } \\
\text { squares }\end{array}$ & $\begin{array}{l}\text { Mean } \\
\text { square }\end{array}$ & $\begin{array}{c}\text { F } \\
\text { value }\end{array}$ & $\begin{array}{r}\text { Prob }>F \\
\text { p-value }\end{array}$ \\
\hline Model & 0.24 & 0.010 & 6.85 & 0.0042 \\
\hline A & $2.162 \mathrm{E}-003$ & $2.162 \mathrm{E}-003$ & 1.41 & 0.2687 \\
\hline B & 0.018 & 0.018 & 11.95 & 0.0086 \\
\hline C & 0.042 & 0.042 & 27.72 & 0.0008 \\
\hline D & 1.240E-004 & $1.240 \mathrm{E}-004$ & 0.081 & 0.7831 \\
\hline$E$ & 0.012 & 0.012 & 7.88 & 0.0230 \\
\hline $\mathrm{F}$ & $2.531 \mathrm{E}-006$ & $2.531 \mathrm{E}-006$ & 1.654E-003 & 0.9686 \\
\hline$A B$ & 4.729E-003 & 4.729E-003 & 3.09 & 0.1168 \\
\hline$A C$ & 5.363E-004 & $5.363 \mathrm{E}-004$ & 0.35 & 0.5702 \\
\hline$A D$ & $1.047 \mathrm{E}-003$ & $1.047 \mathrm{E}-003$ & 0.68 & 0.4322 \\
\hline $\mathrm{AE}$ & 4.883E-004 & 4.883E-004 & 0.32 & 0.5876 \\
\hline $\mathrm{AF}$ & $5.778 \mathrm{E}-005$ & $5.778 \mathrm{E}-005$ & 0.038 & 0.8508 \\
\hline $\mathrm{BC}$ & $1.531 \mathrm{E}-006$ & $1.531 \mathrm{E}-006$ & $1.001 \mathrm{E}-003$ & 0.9755 \\
\hline $\mathrm{BE}$ & 1.526E-003 & $1.526 \mathrm{E}-003$ & 1.00 & 0.3471 \\
\hline$C D$ & 0.013 & 0.013 & 8.66 & 0.0186 \\
\hline CE & 5.330E-003 & $5.330 \mathrm{E}-003$ & 3.48 & 0.0989 \\
\hline $\mathrm{DE}$ & $2.433 \mathrm{E}-003$ & $2.433 \mathrm{E}-003$ & 1.59 & 0.2429 \\
\hline DF & 0.015 & 0.015 & 9.70 & 0.0144 \\
\hline $\mathrm{EF}$ & 0.021 & 0.021 & 13.70 & 0.0060 \\
\hline $\mathrm{ABC}$ & 0.010 & 0.010 & 6.71 & 0.0321 \\
\hline $\mathrm{ABE}$ & 0.011 & 0.011 & 6.99 & 0.0295 \\
\hline$A C D$ & 0.040 & 0.040 & 26.31 & 0.0009 \\
\hline ADE & 0.014 & 0.014 & 9.14 & 0.0165 \\
\hline AEF & 0.026 & 0.026 & 16.80 & 0.0034 \\
\hline \multicolumn{5}{|l|}{$P<0.05$} \\
\hline Std. Dev. & 0.039 & & R-Squared & 0.9517 \\
\hline Mean & 0.38 & & Adj R-Squared & 0.8128 \\
\hline c.v. & 10.27 & & Pred R-Squared & 0.2271 \\
\hline PRESS & 0.20 & & Adeq Precision & 11.831 \\
\hline
\end{tabular}


Figure 2 shows main interaction plots between $\mathrm{KH}_{2} \mathrm{PO}_{4}$ and sodium acetate, dextrose and sodium acetate, dextrose and $\mathrm{NaHCO}_{3}$. Figure 3 is a parity plot for P10 medium by two level factorial designs. Actual value is close to the predicted value that has been given by model so the model has been fitted very well as per Table 10.

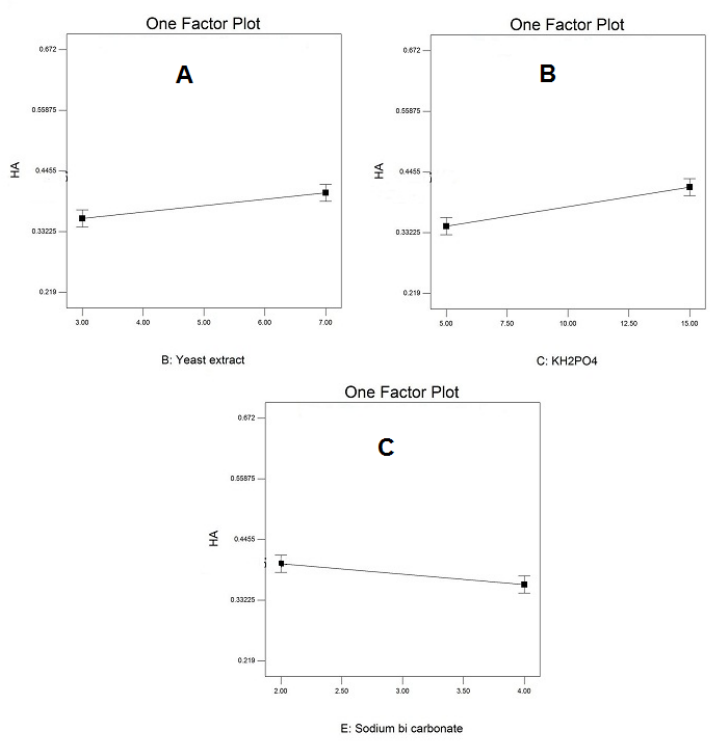

Figure 1. Main effect plot showing the effect of (A-Yeast extract, $\left.\mathrm{B}-\mathrm{KH}_{2} \mathrm{PO}_{4}, \mathrm{C}-\mathrm{NaHCO}_{3}\right)$

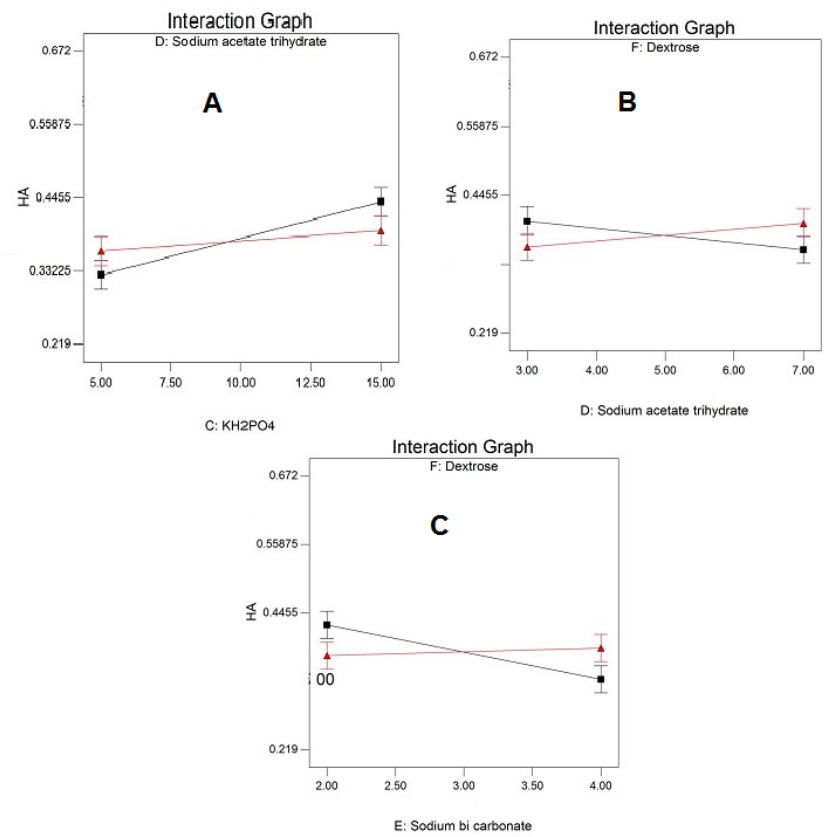

Figure 2. Main interaction plot between $\left(\mathrm{A}-\mathrm{KH}_{2} \mathrm{PO}_{4}\right.$ and sodium acetate, $\mathrm{B}$-Dextrose and sodium acetate,C-Dextrose and sodium bicarbonate)
The overall production of the HA is dependent on the nitrogen sources available in the media. The carbon source value selected in the experiment was in an optimum range in which the maximum activity will be achieved (Jagannath and Ramchandran, 2010). There are very few reports on statistical optimization of the media on HA production through full factorial design, response surface methodology and other optimization designs.

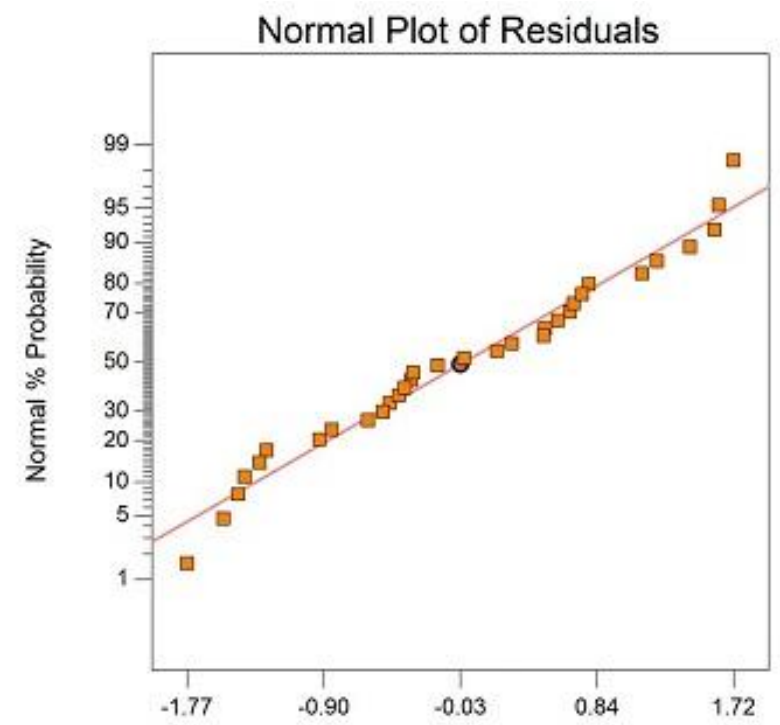

Studentized Residuals

Figure 3. Normal plot Vs residulas

Radial basis function coupled with neural network quantum based particle swarm optimization (RBFQPSO) studies on the media requirements especially over the influence of amino acids on the production of HA was carried out by Liu et al., (2009). The predicted maximum HA yield was $6.92 \mathrm{~g} / \mathrm{L}$ when arginine 0.062 $\mathrm{g} / \mathrm{L}$, cysteine $0.036 \mathrm{~g} / \mathrm{L}$, and lysine $0.043 \mathrm{~g} / \mathrm{L}$ was added. The optimal amino acids addition allowed HA yield increased from $5.0 \mathrm{~g} / \mathrm{L}$ of the control to $6.7 \mathrm{~g} / \mathrm{L}$ in the validation experiments.

Table 10. Point prediction for P10 medium

\begin{tabular}{|cccc|}
\hline $\begin{array}{c}\text { Run } \\
\text { no. }\end{array}$ & $\begin{array}{c}\text { Predicted value range } \\
(\mathbf{g} / \mathbf{L})\end{array}$ & $\begin{array}{c}\text { Actual value } \\
(\mathbf{g} / \mathbf{L})\end{array}$ & $\begin{array}{c}\text { Mean actual value } \\
(\mathbf{g} / \mathbf{L})) \pm S D\end{array}$ \\
\hline 1 & $0.18-0.64(0.411)$ & $0.356,0.299,0.446$ & $0.367 \pm 0.070$ \\
2 & $0.12-0.58(0.35)$ & $0.322,0.494,0.419$ & $0.447 \pm 0.090$ \\
3 & $0.14-0.6(0.37)$ & $0.549,0.330,0.276$ & $0.385 \pm 0.140$ \\
4 & $0.17-0.63(0.4)$ & $0.322,0.24,0.334$ & $0.299 \pm 0.050$ \\
\hline
\end{tabular}

The optimization of fermentation conditions was carried out by Liu et al., (2009) and found that RBF-QPSO 
studies gave better optimization than that of RSM. The predicted maximum HA yield by RSM and RBF-QPSO was 5.27 and $5.62 \mathrm{~g} / \mathrm{L}$, respectively, while a maximum HA yield of 5.21 and $5.58 \mathrm{~g} / \mathrm{L}$ was achieved in the validation experiments under the optimal culture conditions obtained by RSM and RBF-QPSO, respectively. Production of HA from Streptococcus zooepidemicus via the supplement of nucleotide bases using response surface methodology (RSM) was studied by Liu et al., (2009). Using a five factorial two level design among the nucleotides uracil was found as the significant variable which was further optimized using RSM.

Optimization of medium for production was using Taguchi orthogonal array design and 24 full factorial designs was reported earlier by Im et al, (2009) and Patil et al, (2011), respectively. In above studies, higher average HA production was observed using high level( $4.5 \%$ ) of glucose, high level ( $4.5 \%$ ) of soya peptone, low level $(0.075 \%)$ of $\mathrm{MgSO}_{4} .7 \mathrm{H}_{2} \mathrm{O}$ and high level $(0.25 \%)$ of $\mathrm{K}_{2} \mathrm{HPO}_{4}$ Soyapeptone $\left(\mathrm{X}_{2}\right)$ had a significant effect $(\mathrm{P}=0.005)$ on $\mathrm{HA}$ yield. $\mathrm{Y}$ as it had the largest coefficient. The maximum average productivity of HA was 0.798 $\mathrm{g} / \mathrm{L}$ in shake flask.

\section{CONCLUSION}

Upon optimization of the components of P10 medium, after $24 \mathrm{hrs}$ of fermentation period, HA yield of $0.70 \pm$ $0.02 \mathrm{~g} / \mathrm{L}$ was obtained. The fractional factorial design revealed that the concentration of yeast extract, $\mathrm{NaHCO}_{3}$ and $\mathrm{KH}_{2} \mathrm{PO}_{4}$ were the significant factors influencing $\mathrm{HA}$ production. Yeast extract, potassium dihydrogen phosphate and sodium bicarbonate are three medium components that shown significant model terms. The factor potassium dihydrogen phosphate was relatively more significant than yeast extract. There are no reports cited for statistical optimization of medium for production of HA by S. equi subsp. zooepidemicus ATCC 39920.

\section{REFERENCES}

Akaska H, Komasaki H, Avali T (1989) Fermentation method for producing hyaluronic acid. U. S. Patent No. 4,801,539.

Armstrong DC, Johns MR (1997) Culture conditions affect the molecular weight properties of hyaluronic acid produced by Streptococcus zooepidemicus. Applied Microbiology and Biotechnology 63: 2759-2764.
Bitter T, Muir HM (1962) A modified uronic acid carbazole reaction. Analytical Biochemistry 4: 330-333.

Chen SJ, Chen JL, Huang WC, Chen HL (2009) Fermentation process development for hyaluronic acid production by Streptococcus zooepidemicus ATCC 39920. Korean Journal of Chemical Engineering 26: 428-432.

Chong BF, Blank LM, Mclaughlin R, Nielsen LK (2005) Microbial hyaluronic acid production. Applied Microbiology and. Biotechnology 66: $341-351$

Duan JX, Yang L, Zhang X, Tan WS (2008) Effect of oxygen and shear stress on molecular weight of hyaluronic acid Produced by Streptococcus zooepidemicus. Journal of Microbiology and Biotechnology 18: 718-724.

Hiroshi M, Masahiro F (1991) Process for preparing hyaluronic acid. U.S. Patent No. 5,071,751.

Huang WC, Chen SJ, Chen TL (2007) Modeling the microbial production of hyaluronic acid. Journal of Chinese Institute of Chemical Engineers 38: 355-359.

Im JH, Song JM, Kang JH, Kang DK (2009) Optimization of medium components for high-molecular-weight hyaluronic acid production by Streptococcus sp. ID9102 via a statistical approach. Journal of Industrial Microbiology Biotechnology 36: 1337-1344.

Jagannath S, Ramachandran KB (2010) Influence of competing metabolic processes on the molecular weight of hyaluronic acid synthesized by Streptococcus zooepidemicus. Biochemical Engineering Journal 48: 148-158.

Kim SJ, Park SY, Kim CW (2006) A novel approach to the production of hyaluronic acid by Streptococcus zooepidemicus. Journal ofMicrobiolology and Biotechnology 16: 1849-1855.

Liu L, Du G, Chen J, Wang M, Sun J (2008A) Influence of modes on microbial production of hyaluronic acid by Streptococcus zooepidemicus. Biotechnology and Bioprocess Engineering 13: 269273.

Liu C, Sun Z, Du J, Wang J (2008B) Response surface optimization of fermentation conditions for producing xylanase by Aspergillus niger SL05. Journal of Industrial Microbiology and Biotechnology.35: 703-711.

Liu L, Du G, Chen J, Wang M, Sun J (2008C) Enhanced hyaluronic acid production by two stage culture strategy based on the modeling of batch and fed batch cultivation of Streptococcus zooepidemicus. Bioresource Technology 99: 8532-8536.

Markovitz AJ, Cifonello JA, Dorfman A (1959) The biosynthesis of hyaluronic acid by group A Streptococcus. Journal of Biological Chemistry 234: 2343-2350.

Nimrods', A, Greenman B, Kanner D, Landsberg M (1988) Ultrapure hyaluronic acid and the use thereof. US Patent No. 4141973. 
O,Regan M, Martini I, Crescenzi F, De Luca C, Lansing M (1994) Molecular mechanism and genetics of hyaluronan biosynthesis. International Journal of Biology and Macromolecules 16: 283-286.

Patil KP, Kamalja KK, Chaudhari BL (2011) Optimization of medium components for hyaluronic acid production by Streptococcus zooepidemicus MTCC 3523 using a statistical approach. Carbohydrate Polymers 86:1573-1577.

Poli S, Bocchiola G, Casareto E, Leoni M, Mazni A, Ronzio E (1996) Process for preparation of hyaluronic acid by fermentation with Streptococcus. European Patent No. 0694616A2.

Rangaswamy V, Jain D (2008) An efficient process for production and purification of hyaluronic acid from Streptococcus equi subsp. zooepidemicus. Biotechnology Letters 30: 493-496.

Rangaswamy V, Jain D (2008B) Optimisation of culture conditions for production and process of purification of high molecular weight hyaluronic acid. US Patent No. 20080138865.

Stahl S (2003) Methods and means for production of hyaluronic acid. US Patent No. 6537795.

Rangaswamy V, Jain D (2008A) Efficient process for purification of high molecular weight hyaluronic acid. Patent No. WO 2008/035372.

Stoolmiller AC, Dorfman A (1969) The biosynthesis of hyaluronic acid by Streptococcus. Journal of Biological Chemistry 244: 236-346.

Swann DA Kuo JW (1991) Hyaluronic acid In: Byrom D (ed), Biomaterials-novel materials from biological sources, Stokton Press, New York, pp 286-305.

Swann DA, Sullivan BP, Jamieson G, Richardson K Singh T (1990) Biosynthesis of hyaluronic acid. US Patent No. 4897349.

Trevelyan WE Forrest RS Harrison JS (1952) Determination of yeast carbohydrates with the anthrone reagent. Nature 170: 626-627.
Trinder P (1969) Determination of blood glucose using an oxidase peroxidase system with a noncarcinogenic chromogen. Annals of Clinical Biochemistry 6: 24-30.

Vazquez JA, Montemayor MI, Fraguas J, Murado MA (2009) High production of hyaluronic and lactic acids by Streptococcus zooepidemicus in fed-batch culture using commercial and marine peptones from fishing by-products. Biochemical Engineering Journal 24: $125-130$.

\section{AUTHORS}

\section{Vinay J. Aroskar, MSc, PhD}

$\mathrm{He}$ is working in Industry since last 25 years. He has specialization in Microbial process development,strain improvement,Scale up based on chemical engineering software,Biotransformations and statistical media optimization. He has expertise in Patent Law.Having work in instrumentation he is also conversant in Regulatory, QA.and GMP audits. He is Technical Expert on Indian Pharmacopea commission and member of Advisory committee at Mitcon, Pune on Biotechnology and Pharmaceuticals. $\mathrm{He}$ is also familiar with Probiotics, Recombinant proteins, steroid transformations and secondary metabolites. He is working on Biopolymer HA since last 10 years.

\section{S.D. Kamat}

She is an Associate Professor and teaching Microbiology at undergraduate and graduate levels since last 30 years. She has worked on several projects funded by various agencies.

\section{D.V. Kamat, PhD}

$\mathrm{He}$ is the Head of Department of Microbiology and is the In - Charge of the Department of Biotechnology. He is the member of board of studies, Microbiology and Member of the Faculty of science in the University of Mumbai. His area of research is Environmental Sciences and Fermentation Technology.

\section{ULIS D-Sorle}

This journal is published by the University Library System of the University of Pittsburgh

as part of its D-Scribe Digital Publishing Program, and is cosponsored by the University of Pittsburgh Press. 